\title{
THE METABOLISM OF METHIMAZOLE IN PREGNANCY
}

We thank Kampmann \& Hansen (1980) for pointing out the misleading statement in our summary when we were comparing the apparent methimazole clearance for the pregnant patients with the nonpregnant patients. The results are not significantly different at the 0.05 level and it would have sufficed to say that the mean apparent clearance in the pregnant patients receiving $10 \mathrm{mg}$ carbimazole was higher than in a comparable group of non-pregnant patients receiving the same dose. The patients in our other study (Skellern, Knight, Low, Alexander, McLarty \& Kalk, 1980) were new hyperthyroid patients who had not previously been treated with carbimazole, and for this study received $60 \mathrm{mg}$ carbimazole: for these reasons a group of patients who had been receiving $10 \mathrm{mg}$ carbimazole daily for a month, were thought to be a better group for comparison.

In other preliminary studies (unpublished results) we have observed differences in apparent clearances of methimazole, at various carbimazole doses, and also since to date no one has reported clearances of methimazole using a specific assay for methimazole, the question of dose-dependent kinetics is open.

We agree that it is difficult to explain some of the results, and that a definitive statement, with respect to metabolism, cannot be made about the higher apparent clearances of methimazole in pregnant patients, since there are too many variables: a small group of patients at different stages of pregnancy, some euthyroid and some hyperthyroid.

\section{G. G. SKELLERN \& B. I. KNIGHT}

Drug Metabolism Research Unit, Department of Pharmaceutical Chemistry, University of Strathclyde, Glasgow.

\section{W. D. ALEXANDER}

University Department of Medicine, Gardiner Institute, Western Infirmary, Glasgow.

Received June 11, 1980

\section{References}

KAMPMANN, J. \& HANSEN, J. M. (1980). The metabolism of methimazole in pregnancy. Br. J. clin. Pharmac., 10, 314.

SKELLERN, G. G., KNIGHT, B. I., LOW, L. C. K., ALEXANDER, W. D., McLARTY, D. G. \& KALK, W. J. (1980). The pharmacokinetics of methimazole after oral administration of carbimazole and methimazole, in hyperthyroid patients. Br. J. clin. Pharmac., 9, 137-143.

\section{EFFECTS OF A SINGLE DOSE OF MIANSERIN ON SLEEP}

Mianserin hydrochloride has been reported to be effective in the treatment of depression when compared with, for example, amitriptyline (Coppen, Gupta, Montgomery, Ghose, Bailey, Burns \& de Ridder, 1976). Smith, Naylor \& Moody (1978) also reported the drug to be an antidepressant, compared with placebo, and suggested that in addition it had sedative and hypnotic properties. The latter conclusion was based mainly on nurse-ratings of sleep duration, although these are known to be unreliable with depressed patients (Kupfer, Wyatt \& Snyder, 1970; Weiss, McPartland \& Kupfer, 1973). Mianserin is now described as a soporific (British Medical Journal, 1980).

In the present study we have used all-night electrophysiological recordings of non-depressed subjects to compare sleep after mianserin and after placebo.

Twelve volunteers, ten females and two males, who considered themselves to be poor or moderate sleepers, were used. They were aged $42-68$, mean 60 years. None were taking psychotropic drugs and all abstained from alcohol for the duration of the study.

Each subject attended the laboratory on three nights, each attendance separated by 1 week. The first night was for adaptation, when subjects received placebo. On the other two nights they received mianserin $30 \mathrm{mg}$ on one night and placebo on the other, in balanced order among the 12 subjects, the tablets being taken $20 \mathrm{~min}$ prior to lights-out. All-night recordings of electro-encephalogram, electro-oculogram and chin electromyogram were made.

Sleep records were later scored blind (Rechtschaffen \& Kales, 1968). Sleep onset latency, REM latency from sleep onset, total sleep time, the duration of each sleep stage and of episodes of wakefulness were computed. The data for sleep latency and REM onset latency were normalized by common log transformation. Comparisons were then made of sleep after mianserin and after placebo, using correlated $t$-tests. 
Table 1 Means in min \pm s.d. (range for sleep onset latency and REM latency)

\begin{tabular}{lcrc}
\hline & $\begin{array}{c}\text { Mianserin } \\
30 \mathrm{mg}\end{array}$ & Placebo & Significance \\
& & & \\
Sleep onset latency $(\mathrm{min})$ & $29.5(17.4)$ & $28.5(14.9)$ & $\mathrm{NS}$ \\
Total sleep time & $462.0(48.3)$ & $454.8(39.2)$ & $\mathrm{NS}$ \\
Total stage 1 sleep & $41.4(17.7)$ & $41.7(20.6)$ & $\mathrm{NS}$ \\
Total stage 2 sleep & $318.4(51.8)$ & $240.8(37.7)$ & $P<0.01$ \\
Total stages 3+4 sleep & $47.4(27.1)$ & $61.6(42.1)$ & $\mathrm{NS}$ \\
REM latency & $252.6(117.0)$ & $69.9(20.2)$ & $P<0.01$ \\
Total REM sleep & $48.3(15.1)$ & $103.1(25.5)$ & $P<0.001$
\end{tabular}

The principal drug-placebo comparisons are shown in Table 1 . Mianserin hydrochloride $30 \mathrm{mg}$ caused a highly significant reduction in total REM sleep $(P<0.001)$. As a percentage of total sleep time, the mean REM duration following mianserin fell from $22.5 \%$ to $10.7 \%(P<0.001)$. The distribution of the effect in terms of cumulative minutes of sleep is shown in Figure 1.

The latency to REM onset, and the duration of stage 2 sleep, were both increased by the drug $(P<0.01)$. Comparisons of sleep onset latency, total

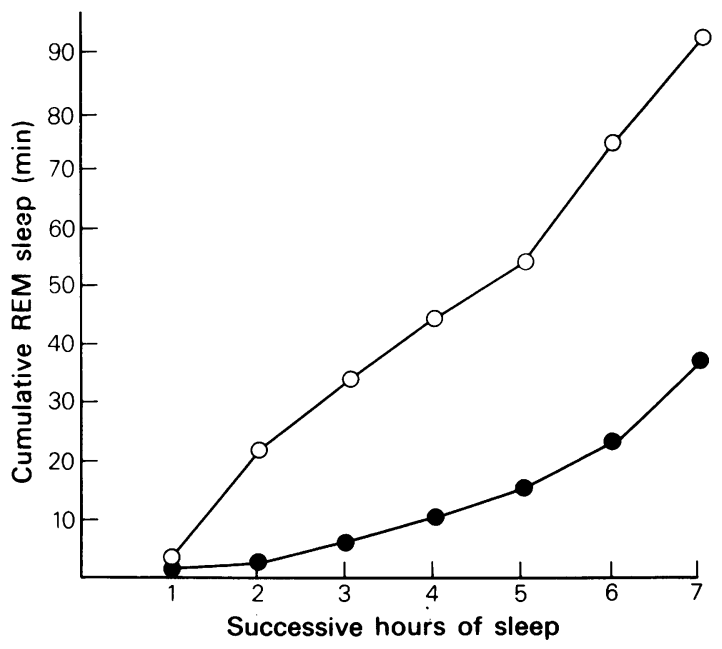

Figure 1 Mean cumulative minutes of REM sleep for placebo $(O)$ and mianserin $(O)$.

\section{References}

BREZINOVÁ. V., ADAM, K., CHAPMAN, K., OSWALD, I. \& THOMSON, J. (1977). Viloxazine, sleep and subjective feelings. Psvchopharmacologv, 55, 121-128.

BRITISH MEDICAL JOURNAL (1980). Hypnotics and hangover. Br. med. J., 1, 743.

CHEN, C. N. (1979). Sleep, depression and antidepressants. Br. J. Psychiat., 135, 385-402. sleep time, the amount of intervening wakefulness and the other non-REM sleep stages under the two conditions did not show significant differences.

The brokenness of each subject's sleep was estimated by calculating the frequency of transitions from any other immediately preceding sleep stage to stage 1 (drowsiness) or to awake. There was no significant difference, mean total arousals were, for drug $=\mathbf{7 4 . 8}$, for placebo 78.0 .

Our findings would not support any belief that mianserin would possess hypnotic properties if taken as a $\mathbf{3 0 ~} \mathrm{mg}$ dose at bedtime. It did not shorten sleep latency, it did not make sleep less broken and it did not increase sleep duration. However, it has frequently been remarked that, whereas reserpine will cause clinical depression and increase REM sleep duration, the drugs that are effective in elevating mood, including dexamphetamine, the tricyclic antidepressants, the MAOIs and viloxazine, (Brezinová, Adam, Chapman, Oswald \& Thomson, 1977) are all expecially potent in reducing the proportion of sleep spent as REM sleep (for reviews, see Vogel, 1975 and Chen, 1979).

The selective effects on human brain function caused by mianserin and reported here are therefore consistent with its clinical use as an anti-depressant.

\section{K. MORGAN, I. OSWALD, SHARON BORROW \& KIRSTINE ADAM}

Department of Psychiatry, University of Edinburgh, Royal Edinburgh Hospital, Morningside Park, Edinburgh $\mathrm{EH} 105 \mathrm{HF}$

Received March 24, 1980

COPPEN, A., GUPTA, R., MONTGOMERY, S., GHOSE, K., BAILEY, J., BURNS, B. \& De RIDDER, J.J. (1976). Mianserin hydrochloride: a novel antidepressant. $\mathrm{Br} . \mathrm{J}$. Psychiat., 129, 342-345.

KUPFER, D.J., WYATT, R.J. \& SNYDER, F. (1970). Comparison between electroencephalographic and systematic nursing observations of sleep in psychiatric patients. 
J. nerv. ment. Dis., 151, 361-368.

RECHTSCHAFFEN, A. \& KALES, A. (1968). A Manual for

Standardized Terminology, Techniques and Scoring System for Sleep Stages of Human Subjects. Washington,

D.C: U.S. Government Printing Office, N.I.H. Publication, No. 204.

SMITH, A.H.W., NAYLOR, G.S. \& MOODY, J.P. (1978).
Placebo-controlled double-blind trial of mianserin hydrochloride. Br. J. clin. Pharmac., 5, 67S-70)S.

VOGEL, G.W. (1975). A review of REM sleep deprivation. Arch. gen. Psvchiat. 32, 749-61.

WEISS, B.L., McPARTLAND, R.J. \& KUPFER. D.J. (1973). Once more: the inaccuracy of non-EEG estimates of sleep. Am. J. Psichiat., 130. 1282-1285.

\section{INFLUENCE OF MESO-CAVAL SHUNT SURGERY ON VERAPAMIL KINETICS, BIOAVAILABILITY AND RESPONSE}

It is now well documented (George, 1979) that for drugs essentially metabolized and having a systemic blood clearance approaching liver blood flow in healthy subjects or patients, when given orally and assuming complete absorption, the bioavailability is low due to the so called 'first-pass' effect. This phenomenon is mainly attributed to metabolism by the liver, although gut-wall metabolism cannot be totally excluded. Thus it is predicted that when the venous return from the stomach, small intestine and colon is diverted past the liver to the vena cava (portacaval shunt), then the bioavailability of high 'firstpass' effect drugs will dramatically increase and may even be complete. However, documentation of this mechanism is incomplete and virtually non-existent in man. Gugler, Lain \& Azarnoff (1975) demonstrated in dogs, that the bioavailability of lignocaine was almost complete after portacaval shunt surgery, whereas antipyrine bioavailability remained complete on both occasions. Salicylamide bioavailability more than doubled to $57 \%$ after shunt surgery, the remaining dose being accounted for by intestinal wall metabolism.

Since there may be significant changes in liver blood flow after construction of a shunt, to study this effect adequately would require that the drug be given intravenously and orally before and after shunt surgery, resulting in extensive blood sampling and thus ethical considerations preclude this study in patients. Hence to date no study of bioavailability after a shunt has been fully presented in humans. We report here for the first time in man a substantial increase in the bioavailability of a normally, highly cleared drug, verapamil, in a single patient before and after shunt surgery, employing a technique whereby the drug is given orally and intravenously at the same time using a stable labelled form of the drug, thus reducing by half the blood sampling volume.

This patient formed part of an extensive study on the disposition and response to verapamil in patients with liver cirrhosis (Eichelbaum et al., unpublished data). The patient was a 44 year old male weighing 62 $\mathrm{kg}$ with severe liver cirrhosis as a result of infectious hepatitis. At the time of the initial study he had oesophageal bleeding due to marked portal hypertension. One week after the initial study (before shunt) because of a deteriorating condition he underwent surgery for a mesocaval shunt. This involved shunting the venous return from the small intestine to the vena cava, thus leaving the venous return from the stomach and colon patent though undefined. As a result of this surgery approximately $70 \%$ of the total venous return was diverted past the liver. Twelve days after surgery the patient was re-investigated. Formal written consent was obtained on both occasions after the patient was informed of the nature and risks of the study.

Both before and after shunt, verapamil was administered simultaneously as an oral and intravenous dose using stable labelled techniques. The intravenous dose was given as an infusion of $10 \mathrm{mg}$ verapamil over $5 \mathrm{~min}$, and a solution of deuterated $\left[\mathrm{D}_{3}\right]$ verapamil was administered orally as $40 \mathrm{mg} 0.5 \mathrm{~h}$ after the intravenous dose. For the estimation of verapamil pharmacokinetics, 16 venous blood samples were taken over the ensuing $24 \mathrm{~h}$. As well, on both occasions, $0.5 \mathrm{mg} / \mathrm{kg}$ indocyanine green was given as a bolus dose with blood samples being taken over 40 min. Finally, before shunt surgery only, antipyrine was administered orally as a solution containing 10 $\mathrm{mg} / \mathrm{kg}$ body weight and saliva samples taken for $48 \mathrm{~h}$. Throughout the time course of verapamil administration, the ECG was monitored and the change in P-R interval was used as a measure of effect. $\left[D_{3}\right]$ verapamil (2,8-bis(3,4-dimethoxyphenyl)-6-methyl2-isopropyl-6-azaoctanitril) was trideuterated in the methoxy group para to the 'quartenary' carbon. Isotopic purity was $98 \%$. Previous experiments in this laboratory showed that this label produced no isotopic effect. Verapamil and $\left[\mathrm{D}_{3}\right]$-verapamil were analysed in plasma by mass fragmentography (Spiegelhalder \& Eichelbaum, 1977) with $d_{7}$-verapamil deuterated in the isopropyl group as the internal standard. Antipyrine in saliva was measured by HPLC (Eichelbaum \& Spannbrucker, 1976). Indocyanine green in plasma was measured spectro- 